\section{Trade Intensity}

What does it tell us? We can think of the trade intensity index as a uniform export share. In other words, the statistic tells us whether or not a region exports more (as a percentage) to a given destination than the world does on average. It is interpreted in much the same way as an export share. It does not suffer from any 'size' bias, so we can compare the statistic across regions, and over time when exports are growing rapidly.

Definition: The trade intensity statistic is the ratio of two export shares. The numerator is the share of the destination of interest in the exports of the region under study. The denominator is the share of the destination of interest in the exports of the world as a whole.

Range of values: Takes a value between 0 and $+\infty$. Values greater than 1 indicate an 'intense' trade relationship.

Limitations: As with trade shares, high or low intensity indices and changes over time may reflect numerous factors other than trade policy.

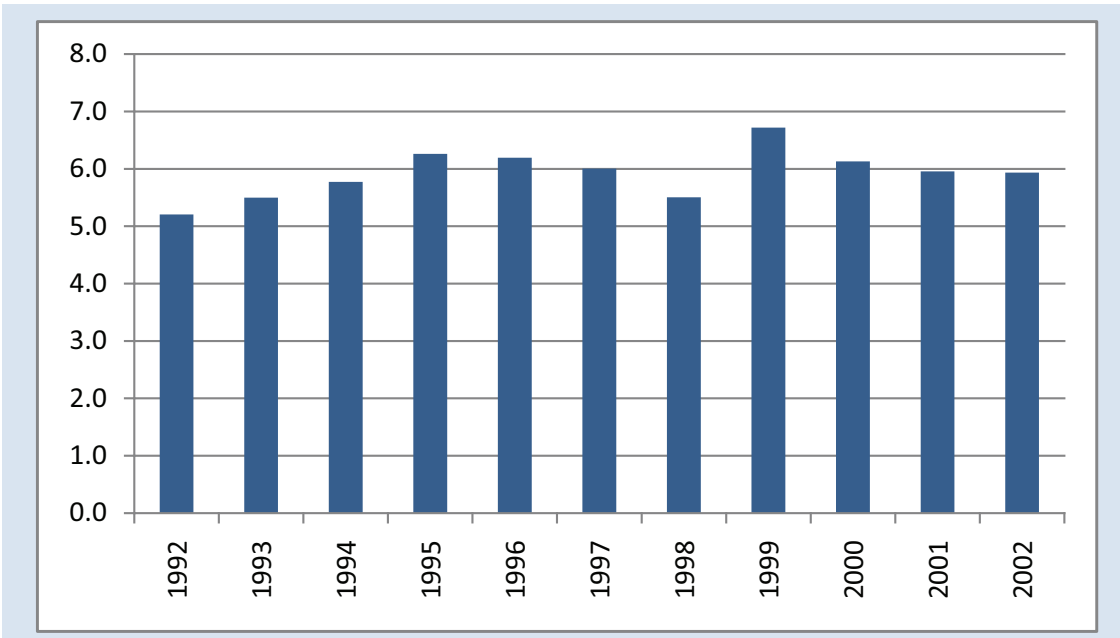

Trade Intensity Index for ANZCERTA (1992-2002)

Example: Suppose that we wish to assess the 'intensity' of trade among the economies of ANZCERTA. The results are in the figure above. Because the index in greater than one, trade within ANZCERTA would be regarded as highly intense. Is this is consequence of the agreement? It is true that the intensity seems to have increased since the agreement was signed in 1993. On the other hand, the index was very high even before then. This probably reflects geographic proximity, and relative isolation from other markets. 


\section{Trade Intensity - Technical Notes}

\section{Mathematical definition:}

$$
\frac{\sum_{\mathrm{sd}} \mathrm{X}_{\mathrm{sd}} / \sum_{\mathrm{sw}} \mathrm{X}_{\mathrm{sw}}}{\sum_{\mathrm{wd}} \mathrm{X}_{\mathrm{wd}} / \sum_{\mathrm{wy}} \mathrm{X}_{\mathrm{wy}}}
$$

Where $\mathbf{s}$ is the set of countries in the source, $\mathbf{d}$ is the destination, $\mathbf{w}$ and $\mathbf{y}$ represent the countries in the world, and $\mathbf{X}$ is the bilateral flow of total exports. In words, the numerator is the export share of the source region to the destination, the denominator is export share of the world to the destination.

Data sources: The United Nations Commodity Trade database (COMTRADE), the International Monetary Fund (IMF) Direction of Trade statistics, the World Trade Database (WTD) maintained by Statistics Canada, and the GTAP database from Purdue University.

\begin{tabular}{l|ccccccc|c|}
\multicolumn{1}{l}{} & Australia & $\begin{array}{c}\text { New } \\
\text { Zealand }\end{array}$ & China & $\begin{array}{c}\text { Rep. of } \\
\text { Korea }\end{array}$ & ASEAN & BIMSTEC & \multicolumn{2}{c}{ ROW } \\
\cline { 2 - 9 } Australia & 0 & 3348 & 4878 & 5213 & 7070 & 1723 & 39339 & 61571 \\
New Zealand & 2564 & 0 & 777 & 659 & 1187 & 171 & 9462 & 14820 \\
China & 6058 & 867 & 0 & 16243 & 23301 & 4317 & 394652 & 445438 \\
Rep. of Korea & 2516 & 301 & 24232 & 0 & 17521 & 2297 & 113180 & 160047 \\
ASEAN & 9850 & 1130 & 24832 & 15950 & 80320 & 7617 & 245645 & 385344 \\
BIMSTEC & 590 & 88 & 2150 & 981 & 4181 & 2115 & 54515 & 64620 \\
ROW & 42455 & 7081 & 154669 & 102757 & 170046 & 38450 & 4246616 & 4762074 \\
Total & 64033 & 12815 & 211538 & 141803 & 303626 & 56690 & 5103409 & 5893914 \\
\hline
\end{tabular}

\section{Simplified Total Trade Matrix (2002)}

Sample calculation: Intra-ANZCERTA exports are highlighted in blue, while total exports from ANZCERTA are highlighted in red. Calculating the export share as before we have $\$ 5912 / \$ 76391 \times 100$ or 7.7 per cent. World exports to ANZCERTA are highlighted green, while total world exports are highlighted in purple. So the world export share to ANZCERTA is $\$ 76848 / \$ 5893914$ or 1.3 per cent. Taking the ratio we have 5.9, this is the trade-intensity index for ANZCERTA in 2002.

Note: In some cases the trade intensity index is adjusted by removing the intra-regional exports from the world total in the denominator. In the example, the denominator in the world export share would be \$5893914-\$5912. Unless the region under study is very large, this adjustment does not make a large difference. Trade intensity can also be calculated using trade shares instead of export shares. 